\title{
"I am not too old to play" - The Past, Present and Future of 50 and Over Organized Sport Leagues
}

\section{Authors' contribution:}
A) conception and design of the study
B) acquisition of data
C) analysis and interpretation of data
D) manuscript preparation
E) obtaining funding

\author{
Evan Webb ${ }^{\mathrm{A}-\mathrm{E}}$, Aida Stratas ${ }^{\mathrm{A}-\mathrm{E}}$, George Karlis ${ }^{\mathrm{A}-\mathrm{E}}$ \\ University of Ottawa, Canada
}

ABSTRACT

The ageing population in Canada is dramatically increasing. According to recent demographic projections, roughly 20 percent of Canada's population will consist of people over the age 65 by 2024 . Indeed, the senior population is expected to surpass that of children under the age of 14 by 2017 . This growth of the senior cohort signals opportunities for individuals over the age of 50 to challenge stereotypes and embrace active living. Organized sport leagues are a means for seniors to not only embrace active living, but to also re-live and continue living the competitive sports that they played earlier in life. The increasing number of organized sport leagues for this cohort, including the active living philosophy embraced by baby boomers, will probably lead to an increased demand for more organized sport opportunities for this population group. The purpose of this paper is to provide a current state of condition of organized sport leagues for those 50 years of age and over. Specifically, the objective of this paper is to present the evolution of organized sport leagues for those 50 and over while also making suggestions for the future provision of such services. It is concluded that: a) more research is needed to better understand the trend of 50 and over sport leagues, b) municipal sport and recreation administrators should consider establishing more 50 and over sport leagues in their recreation program delivery systems, c) 50 and over sport leagues should better address the needs of specific population groups (e.g., women and ethnic groups), and d) awareness should be enhanced for potential entrepreneurial opportunities for the establishment of 50 and over sport leagues.

KEYWORDS

\section{Introduction}

A few decades ago, ageism was seen as an unpleasant social problem in many countries around the world, and the sight of a group of older men or women playing sports or jogging down the street would have been strikingly unusual (Butler 1969; Lagacé 2015). Prevailing socio-cultural attitude at the time reinforced the perception that older adults near, or at, retirement, were expected to retreat into a quiet and inactive life 
playing predominantly the role of grand-parents, or resting in a comfortable rocking chair (Butler, 1969; Chodzko-Zajko \& Schwingel 2015). Thus the fitness and sport needs of older adults were unrecognized.

Indeed, prior to the surge in the over 65 population the notion of ageing, according to Butler (1969), represented "a deep seated uneasiness on the part of young and middle-aged - a personal revulsion to and distaste for growing old, disease, disability; and fear of powerlessness, "uselessness," and death (p. 243). Over time these traditional and outdated stereotypical feelings have changed to reflect a more positive attitude towards ageing due to a growing body of research pointing to the health hazards of a sedentary lifestyle and the importance of embracing physical activity at any age. There is now abundant evidence insisting that older adults may be able to control how quickly they decline and that "the physiologic changes previously associated with ageing are actually due to disuse" (Cooper, Powell, \& Rasch 2007, p. 393).

The year 1999 served as a launching date for global organisations such as the World Health Organisation (WHO) and the United Nations. Working closely together, these organizations sparked a global positive ageing movement through a series of health promotion events that took place in several countries around the world. More specifically, the year 1999 highlighted a shift toward appreciating the ageing process. According to Alexandre Sidorenko, a UN expert on ageing, the year acted as "a springboard for launching a wide variety of long term strategies on ageing at both national and international levels" (Chodzko-Zajko 2000, p. 334). As a result, a series of walks were organized worldwide that year as a WHO initiative during the UN's International Year of Older Persons collectively known as the Global Embrace (WHO 2001). These walks began on October 2nd, 1999 in New Zealand followed by Australia, Japan, China, India, Africa, the Middle-East, Europe, the United States, and Latin America (Chodzco-Zajko 2000). Both events underscored the importance of embracing ageing and eliminating negative stereotypes.

The astounding growth of the older adult population has become even more evident today as the pace of growth has increased steadily worldwide since 1999. According to WHO the proportion of individuals aged 60 years and over has increased faster than any other age group in practically all regions around the world but mostly in developed countries (WHO 2016). In Canada, for the first time ever, in 2015, the percentage of baby boomers (those born in the two decades after the Second World War between 1946 -1965) has exceeded persons aged 15 years and under (Statistics Canada 2015). Further, adults over the age of 85, that is, the "the oldest-old" (Baker, Horton \& Weir 2009, p. 7), represented the fastest growing segment of the population.

In order to adapt to the socio-economic challenges of an increasingly ageing population, an approach to physical and mental fitness will take on much more importance as older adults attempt to optimize their health and functional ability to prolong their lifespan and reduce risks associated with chronic diseases (Baker, et al. 2009; Dionigi, Horton, \& Baker 2013). Organized sport leagues are a means for seniors to not only embrace active living, but to also re-live and continue living the competitive sports that they played earlier in life. The increasing number of organized sport leagues, the historical impact of the Masters Sports and Seniors Games movements and the active living philosophy embraced by baby boomers has led to an increased demand for a variety of sport programs for this population group.

The purpose of this paper is to provide a current state of condition of organized sport leagues for those 50 years of age and over. Specifically, the objective of this paper is to present the evolution of organized sport leagues for those 50 and over while also making suggestions for the future provision of such services. To fulfil this purpose and objectives, the main body of this paper is divided into three parts: a) a literature review on sports for ageing adults including a description of the evolution of organized sport for older adults, b) an overview of the current state of condition, and c) suggestions for the future provision of organized sport leagues for older adults.

\section{Literature Review - Sports for Ageing Adults}

A number of recent research studies have examined older adults' experiences of participation in sports later in life. For instance, Dionigi (2003) found that older adults can simultaneously delay, rethink, and accept the ageing process through sports participation. Wearing (1995) showed how older adults can resist negative ageist beliefs through continuous sports involvement. Results from Eman's (2012) study revealed how 
participating in sports for competitive purposes allowed older players to focus mainly on their physical capabilities to avoid being viewed as old and weak, and by doing so, overcoming old age stereotypes relevant to body image and appearance. Similarly, Dionigi's (2006) findings have shown how older adults pursued competitive sport as a way of actively resisting constraint and oppression arising from negative factors related to old age and concluded how sports later in life is used as a form of empowerment. However, results from Grant (2001) showed mixed outcomes arguing that older adults' experiences of sports participation are "expansive, dynamic, and imbued with multiple interpretations" (p. 222). While the majority of research addressed sports participation later in life as a means to resist the process of ageing at an individual and sociocultural level, more empirical research is needed to understand the experiences of older adults' participation in organized recreational sport leagues

\section{The Evolution of Organized Sport for Older Adults}

In the latter part of the $20^{\text {th }}$ century there was an increase in the number and popularity of sports participation and competitions for middle-aged adults and seniors (Pfister 2012). This was evident not only in the creation of competitions such as the Masters games which today occurs worldwide for individuals aged 35 years and over (and recently for 30 to 34 years olds who are dubbed sub-masters) but also through other organizations as well such as the National Senior Games Association (NSGA) and the National Senior Athletes Association (NSAA). However, this trend has no doubt been inspired by the Masters Sport movement that originated in the 1960s in Western countries. Indeed, the idea that sports and fitness activities are the domain of the "young and the restless" has become a dispelled myth and the new sporting ethos "sports for all" has emerged instead challenging some of the traditionally held views on active ageing. In fact, "sports for all" has been adopted as one of the primary goals of the World Masters Games - the largest international competitive multi-game event for older adults held every four years to encourage athletes past their prime age to compete in their favorite sport (Heazlewood et al. 2011).

Masters sport was introduced in North American societies in the mid-1960s for players who exceeded the optimal age of an elite athlete (Baker et al., 2009; Dionigi et al. 2013). Age is a significant determining factor in admitting players or limiting their participation into sports leagues. Typically, the age of peak for league players varies between 23 and 29 years depending on the type of sport played (Kuper 2011). Historically, many athletes past their prime age were expected to retire from playing competitive sports. In fact, prior to 1966, sports leagues for mature players were virtually non-existent. It was not until a prominent American lawyer, David Pain, founded the first "Masters Mile" for competitive male runners and set the minimum age for participation at 40 (women were initially denied participation). The event took place on June 11, 1966 at the Balboa Stadium in San Diego and proved to be an immense success, with over twenty thousand spectators attending (Higdon 2005; Olson 2001). Pain coined the concept "Masters Mile" to avoid labelling athletes as seniors or veterans (Olson 2001). The Masters Mile evolved to include a wider range of track and field activities eventually being renamed Masters Track and Field. These games quickly spread to other parts of the United States. By 1968, the first annual U.S.A. Masters Track and Field Championships took place from July 19-20 (Olson 2001). According to Pain, the Masters events were enormously successful as they "demonstrated that older adults could engage in all the established track and field disciplines and that there was no valid basis for excluding them from competition" (Olson 2001, p. 17). By 1972, Pain along with his wife Helen had organized the first international Masters track and field tour that took place in eight European cities (London, Helsinki, Stockholm, Oslo, Sarpsborg, Gothenburg, Copenhagen, and Cologne). The tour began in London on August 21 and ended in Cologne on September 17. One hundred and fifty two athletes participated in the tour. Among these competitors were 32 Canadians, 114 Americans, and 38 from different countries including Australia, England, and West Germany. These international competitive games had ignited the Masters Track and Field movement globally. In 1975, the first World Masters Championships were held in Toronto, Canada from August 11 to 16. One thousand and four hundred athletes (men and women) from 32 countries participated. 
Coincidently, as the Masters Track and Field organization was being established, the Masters Swimming program in the United States was being founded in 1970 by a San Diego doctor, Ransom J. Arthur. His mission was to promote the health and well-being of older swimmers, build friendships, and sustain competition (Cooper et al. 2007). The first U.S. Masters National Championship was held on May 2nd-3rd in 1970 at Amarillo, Texas. In 1971, a Canadian law professor, Hud Stewart, founded the first Masters swimming program in Toronto. The concept became popular across the Canadian provinces.

The development of Masters Track and Field along with Masters Swimming paved the way for other Masters athletic events at both competitive and non-competitive levels. In 1985, the first international multisport event known as the World Masters Games was held in Toronto for those over the age of 35, and up to the age of the oldest athlete. Typically, at the Masters level, age groups for sports teams are organised in 10year intervals (e.g. 35-44 years, 45-54 years, and so forth) while other competitive events such as swimming, running, track and field, and so on, are set in 5-year intervals (e.g. 25-29 years, 30-34 years, and so on; Cooper et al. 2007; Dionigi et al. 2013).

The emergence of the three major Masters sports (Track and Field, swimming, and World Games) encouraged athletic institutions across Canada to organize athletic programs and various sports for older persons. These were geared to those seeking to pursue sports and physical activity as serious leisure requiring sustained and committed involvement, or for those desiring to pursue activities recreationally for their perceived health and fitness benefits as they age. According to Baker, et al. (2009), Masters sports' players have come to "represent an intriguing group for researchers due to the fact that they represent some of society's most successful agers, at least from a physical standpoint" (p. 10).

Another existing multi-sport organization is the National Seniors Games Association (NSGA) in the U.S. The organization began in 1985 in St. Louis, Missouri with the intention of promoting healthy lifestyles for adults through education, fitness and sport. Today the NSGA is a non-profit organization that continues to motivate older adults, aged 50 and over, into active and healthy lifestyles through seniors games. The biennial games are a sporting competition consisting of nineteen major sports events for men and women (over 50). These games have become the largest multi-sport event for seniors in the world.

The National Senior Athletes Association (NSAA), also based out of the U.S., was founded in 2012 with the purpose of benefiting senior athletes and the promotion of senior sports for individuals over 50 years old. The association's activities seek to improve senior sport participation and fitness levels for members (e.g., providing expert sports and fitness instruction, inspiration and motivation, products and services) while also working with other organizations to provide seniors games and other services to raise awareness and funds for senior sports (National Senior Athletes Association 2017).

\section{Current State of Condition}

Today one can find a proliferation of sports programs distinctly for older adults separate from leagues that include individuals who could be considered younger adults (i.e., 18 - 35 years old) in an attempt to keep competition levels fair. What is offered by various municipal community centres and private or non-profit sport centres are sports leagues only for adults above 35 years old and in some cases sports leagues for adults aged 50 and over. These aged stratified leagues are a response to increased demand for competitive sport programs by the steadily increasing ageing population (i.e., the baby boomer generation) along with the knowledge developed over the years that sports are beneficial for older adult's health, wellness, and quality of life. It is also a recognition that, despite the fact that this ageing population is completely capable of participating in competitive sports, their athletic ability and advancing physique leave them at a competitive disadvantage compared to younger adults who are in their peak performance. For this reason it is surprising to see that, even though most organizations in Canada providing recreational sports make programs available to adults, most still do not have leagues limited to participants over age 35 or over age 50 but instead offer programs integrating all adults of all ages (though typically they are still separated by sex).

An increased risk of injury in older athletes is another reason why a lack of age-separated leagues seems unreasonable. Various over 35 or over 50 sports leagues implement special rules that take into account the 
increased chances of injury that ageing adult participants are more susceptible too. For instance, in an over 50 hockey league in Ottawa, Ontario, Canada there is a rule in place, for safety purposes, where the game must be paused if any participants have fallen on the ice and remains paused until they are up or escorted off of the rink. Considering this age strata is more susceptible to intensely debilitating hip injuries and the like, it is reasonable for this rule to be in place. This rule would likely not be enforced, and typically is not, in an adults of all age's league which can be very dangerous to the older adults who may be participants in such a program. There is value in offering sport programs that separates adults from each age group and we are seeing a trend in the right direction with several community centres, sport centres, and existing athletic competitions for adults over 35 and 50. However, considering how prevalent this population is about to become in addition to the health and wellness benefits that sports can offer them, it may be in the best interest of more recreation providers to consider separating adults into differing age strata when it comes to the delivery of recreational sport programs.

There are various examples of recreational sport programs devoted to adults of certain ages in Canada. Sport and Social Clubs, which operate out of most Canadian towns and cities, specialize in offering recreational competitive sports to adults within their communities. The Ottawa and Edmonton iterations of Sport and Social Clubs offer a 'League of Legends' and 'Legends' program respectively which are devoted to offering most mainstream sports only to adults aged 35 and over (Edmonton Sport and Social Club 2017; Ottawa Sport and Social Club 2017). Tennis Canada, the official leading body for tennis in Canada, also overlooks various seniors' tennis tournaments and competitive programs. In line with the rules set out by The International Tennis Federation ("ITF"), competitions are organized into the following age groups: 35-39, 40-44, 45-49, 50-54, 5559, 60-64, 65-69, 70-74, 75-79 and 80 and up (Tennis Canada, 2016). Another private organization operating out of Canada and the United States, The Adult Safe Hockey League (ASHL), is the largest recreational hockey league in the world with about 63,000 players. Age-restrictive divisions including 30+, 40+, and 50+ categories are available in the ASHL in addition to 5 distinct skill tiers between first timers and pros (Canlan Ice Sports Corporation 2017). Sport leagues for older adults are also offered in Canada through municipal community centres, private organizations, and non-profits (e.g., YMCA). Nevertheless, as indicated above, the amount of these organisations offering programs only to adults of certain age groups (e.g., 35 and above or 50 and above), though increasing, is still lacking. Regardless, the city of Ottawa is an example of a municipality that offers sports for individuals specifically over the age of 50 through its various community centres including badminton, basketball, cross country skiing, hockey, skating, and soccer programs (City of Ottawa 2016).

\section{Suggestions for Future Provision of Organized Sport Leagues for Older Adults}

\section{More research is needed to better understand the trend of 50 and over sport leagues.}

Although interest in organized sport activities for older adults came to the forefront in the 1960s, it was not until the 1980s when research on sports for ageing populations started to take off. The past four decades have witnessed a steady increase in this research thanks in large to the growing awareness of the needs of an ageing baby boomer generation. Demographers such as David Foot have indicated that sport, fitness, and active living will be a part of the lifestyle ageing baby boomers will expect and demand. It is for this reason that Foot, in his year 2000 edition of Boom, Bust and Echo predicts that home fitness for an ageing population is a future activity trend that will be popular for baby boomers. Recently, the increasing popularity among the ageing population of organized sport leagues has justified the need for more research in this area. To date minimal research has focused on understanding the needs, demands, and interests of those who participate or want to participate in organized sport leagues for adults age 50 and over.

2. Municipal sport and recreation administrators should consider establishing more 50 and over sport leagues in their recreation program delivery systems.

Municipal recreation departments such as the City of Ottawa's recreation unit have done an excellent job in increasing the number of sport, leisure, and recreation activities offered for the 50 plus cohort during the past 10 years. Most of these activities however focus on individual sports and fitness. Although some 
municipality operated sport leagues exist for adults 50 and over in Canada, a need for more will continue to grow as the population continues to age. It is acknowledged that many recreational services that do implement programs for individuals of older age groups often experience a lack of enrollment and attendance and thus the presence of these programs becomes unjustified. However, municipal sport and recreation directors would be wise to employ market analysis surveys to recognize the need and demand for such organized sport leagues in their respective communities.

3. Enhance the number of 50 and over sport leagues to better address the needs of specific population groups such as women and ethnic groups.

Canada's ageing population will offer challenges, changes, and potential for growth. These opportunities should also focus on addressing the needs of a diverse and pluralistic population. More recently, Canada has witnessed a growth in men's over 50 hockey leagues. It is highly likely that as the population ages, a growing need will persist for over 50 women's hockey leagues as the past 20 years has seen an increase in the number of women playing. Further, there may be a future need for the establishment of hockey leagues for Canada's ethnic population over the age of 50. Currently, ethno-specific leagues such as Toronto's Multicultural League and the Ottawa Hellenic Athletic Association hockey leagues consist of ageing players competing with younger adults. A future need is thus likely for the establishment of ethno-specific hockey league branches with divisions for adults over 50 .

4. Awareness to be enhanced for potential entrepreneurial opportunities for the establishment of 50 and over sport leagues.

For entrepreneurs, ageing will present new opportunities. Being prepared to serve the needs of a growing senior population requires understanding and recognizing activity trends, needs, and wants. Current trends reveal a growing interest for the over 50 population to participate in organized sports such as hockey leagues. This trend will more than likely continue to be the case in the future, meaning that a need will exist to enhance the number of over 50 sport leagues. Although private sector entrepreneurs may gain financially from the development of such leagues, the public and non-profit sectors could also act as further alternatives for providing such services to address this growing need.

\section{REFERENCES}

Butler, R. (1969). Ageism: Another form of bigotry. The Gerontologist, 9, 243- 246.

Baker, J., Horton, S., \& Weir, P. (2009). The masters athlete: Understanding the role of sport and exercise in optimizing aging. New York, NY: Routledge.

Canlan Ice Sports Corporation (2017). Welcome to the world's largest rec hockey league. Retrieved from http://ashl.adultrechockey.ca/season-details-s13217

Chodzko-Zajko, W. (2000). Successful aging in the new millennium: The role of regular physical activity. Quest,52(4), 333-343.

Chodzko-Zajko, W., \& Schwingel, A. (2015). Active aging history. Retrieved from: http://www.humankinetics.com/active-aging-history

City of Ottawa. (2016). Older adult activity guide for adults over 50: Fall 2016 and Winter 2017. Retrieved from http://documents.ottawa.ca/ sites/ documents.ottawa.ca/files/fw2016_olderadultactivity_en.pdf

Cooper, L.W., Powel, A.P., \& Rasch, J. (2007). Master's swimming: An example of successful aging in competitive sport. Current Sports Medicine Reports, 6(6), 392.

Dionigi, R.A. (2006). Competitive sport as leisure in later life: Negotiations, discourse, and aging. Leisure Sciences, 28, 181-196.

Dionigi, R.A. (2003). Resistance and empowerment through leisure: The meaning of competitive sport participation to older adults. Society and Leisure, 25(2), 303-328.

Dionigi, R.A., Horton, S., \& Baker, J. (2013). Negotiations of the ageing process: Older adults' stories of sports participation. Sport, Education and Society, 18(3), 370-387.

Edmonton Sport and Social Club (2017). Legends 35+ Home. Retrieved from https://www.edmontonsportsclub.com/leagues/legends 
Eman, J. (2012). The role of sports in making sense of the process of growing old. Journal of Aging Studies, 26(4), 467475 .

Foot, D. (2000). Boom, bust, and echo 2000. Toronto, ON: Macfarlane, Walter \& Ross.

Goodsell, T.L., Harris, B.D., \& Bailey, B.W. (2013). Family status and motivations to run: A qualitative study of marathon runners. Leisure Sciences, 35, 337-352.

Grant, B. (2001). Youre never too old: Beliefs about physical activity and playing sport in later life. Ageing and Society, 21(6), 777-798.

Heazlewood, I., Walsh, J., Climstein, M., Burke, S., Adams, K. \& DeBeliso, M. (2011). Sport psychological constructs related to participation in the 2009 World Masters Games. World Academy of Science, Engineering and Technology, 77 , 970-973.

Higdon, H. (2005). Masters running: A guide to running and staying fit after 40. Emmaus, PA: Rodale Books.

Kuper, S. (2011). The optimal age to be an athlete. Retrieved from http://ca.askmen.com/sports/fanatic_300/325_thebest-age-for-athletes.html

Lagacé, M. (2015). Représentations et discours sur le vieillissement : La face cachée de l'âgisme? Québec City, PQ: Presses de l'Université Laval.

National Senior Athletes Association. (2017). About the NSAA. Retrieved from http://mynsaa.org/about/

National Senior Games Association. (2017). History of the NSGA. Retrieved from http://nsga.com/about/2016-04- 2013-53-38/history

Pfister, G. (2012). It is never too late to win: Sporting activities and performances of ageing women. Sport in Society, 15(3), 369-384.

Olson, L. (2001). Masters track and field: A history. Jefferson, NC: London: McFarland.

Ottawa Sport and Social Club. (2017). All-sorts-of sports: League of legends 35+. Retrieved from https://ossc.ca/register/more/166

Singleton, J.F. (1985). Activity patterns of the elderly. Loisir et Société/Society and Leisure, 8(2), 803-819.

Statistics Canada. (2015). Canada's population estimates: Age and sex, July 1, 2015. Retrieved from http://www.statcan.gc.ca/dailyquotidien/150929/ dq150929b-eng.htm

Tennis Canada. (2016). Seniors tennis. Retrieved from http://www.tenniscanada.com/competitive/seniors/

The World Health Organization. (2001). The WHO global embrace. Retrieved from http://www.who.int/ageing/publications/global_embrace/en/

The World Health Organization. (2016). Health topics: Ageing. Retrieved from http://www.who.int/topics/ageing/en/

Wearing, B. (1995). Leisure and resistance in an ageing society. Leisure Studies, 14(4), 263-279.

AUTHOR'S ADDRESS: $\quad$ Evan Webb

University of Ottawa

10 Fogerty Street, Brampton ON

Canada, L5W 1P2

E-mail: ewebb015@uottawa.ca

Received: 17 April 2017; Accepted: 17 May 2017 